\title{
Eighteenth Conference of Arab Red Crescent and Red Cross Societies
}

The Eighteenth Conference of Arab Red Crescent and Red Cross Societies was held in Doha (Qatar) from 2 to 5 March under the patronage of His Excellency Khalifa Bin Hamad Al Thani, Emir of the State of Qatar. The Conference was organized jointly by the Qatar Red Crescent Society and the General Secretariat of Arab Red Crescent and Red Cross Societies under the direction of Mr. Abdel Ghani Ashi, General Secretary.

The National Societies of the following countries were represented at the Conference: Algeria, Bahrain, Djibouti, Egypt, Iraq, Jordan, Kuwait, Libya, Mauritania, Morocco, Pakistan, Qatar, Saudi Arabia, Sudan, Syria, Tunisia, Turkey, United Arab Emirates, The Yemen Arab Republic, the People's Democratic Republic of Yemen and the "Palestinian Red Crescent". Representatives from several National Societies in Europe, Asia, Africa and the Americas, as well as from UNICEF, attended the Conference as observers.

The ICRC delegation included Mr. A. Hay, President, Mr. C. Sommaruga, President-elect, Mr. Amiguet, Mr. Nessi, Mr. Tschiffeli and Mr. Mériboute. The League was represented by Mr. E. de la Mata, President, Mr. H. Hoegh, Secretary General, Mr. Kisselev, Mr. Yalgin, Mr. Said Ali and Mrs. Camporini.

The opening session was marked by speeches from $\mathrm{Mr}$. Ahmed El Ansari, the Qatar Minister of Labour and Social Welfare, who represented the Emir of Qatar, Dr. Ahmed Abou-Goura, Chairman of the Standing Commission of the Red Cross and Red Crescent, Mr. E. de la Mata and Mr. A. Hay. The ICRC President took the opportunity to bid farewell to the participants, thank them for their contributions and introduce his successor. He then spoke about ICRC activities in the Middle East. Mr. M. Amiguet, the delegate-general for the Middle East, enlarged on the President's report. 
There was also discussion of the League's report on its activities in the Islamic world, of working documents presented by National Societies relating to humanitarian issues, of support for the "Palestinian Red Crescent", etc.

Following the discussions, the participants approved a number of resolutions, two of which concern the ICRC. The first, after paying tribute to the ICRC's work in the region, asks the institution to step up its efforts for the protection of civilians in southern Lebanon and in the occupied territories. Urging co-operation between the ICRC and the General Secretariat of Arab Red Crescent and Red Cross Societies, the Conference reaffirmed the National Societies' support for the ICRC in the application of the Geneva Conventions and the Principles of the International Red Cross and Red Crescent Movement. It asks Arab States to co-operate with the ICRC by facilitating its humanitarian activities and encourages the States which have not yet ratified the Protocols additional to the Geneva Conventions to do so.

The second resolution recommends that the National Societies take all necessary measures to prevent their members and the general public from misusing the emblem. This is in order to safeguard its capacity to provide protection.

It should be added that the Statutes of the Conference of Arab Red Crescent and Red Cross Societies were amended, and the General Secretary's term of office was extended from four to six years. It was also decided that the Conference will in future be held every year, alternately in an Arab country (Egypt in 1988) and in Geneva to coincide with the League General Assembly. 